\title{
BMJ Open Epidemiology and disease burden of complex wounds for inpatients in China: an observational study from Sichuan province
}

\author{
Qingling Jiang (D) , ${ }^{1,2}$ Jo C Dumville, ${ }^{3}$ Nicky Cullum, ${ }^{3}$ Jay Pan (D) , ${ }^{1,2}$ Zhenmi Liu ${ }^{1}$
}

To cite: Jiang Q, Dumville JC, Cullum N, et al. Epidemiology and disease burden of complex wounds for inpatients in China: an observational study from Sichuan province. BMJ Open 2020;10:e039894. doi:10.1136/ bmjopen-2020-039894

- Prepublication history and additional materials for this paper is available online. To view these files, please visit the journal online (http://dx.doi. org/10.1136/bmjopen-2020039894).

Received 30 April 2020 Revised 08 August 2020 Accepted 16 October 2020

Check for updates

(C) Author(s) (or their employer(s)) 2020. Re-use permitted under CC BY-NC. No commercial re-use. See rights and permissions. Published by BMJ.

${ }^{1}$ West China School of Public Health and West China Fourth Hospital, Sichuan University, Chengdu, China

${ }^{2}$ West China Research Center for Rural Health Development, Sichuan University, Chengdu,

China

${ }^{3}$ Division of Nursing, Midwifery and Social Work, School of Health Sciences, Faculty of Biology, Medicine and Health, University of Manchester, Manchester Academic Health Science Centre, Manchester, UK

Correspondence to Dr Zhenmi Liu; zhenmiliu@scu.edu.cn and Professor Jay Pan; panjie.jay@scu.edu.cn

\section{ABSTRACT}

Objectives To investigate the period prevalence of complex wounds among the overall inpatients, and the impact of complex wounds on inpatient health expense and length of hospital stay (LOS).

Design An observational study.

Setting 6056 healthcare institutions across Sichuan province in China.

Participants This study included 4033763 people admitted to healthcare institutions during 1 September 2018 and 31 December 2018.

Results The point prevalence of complex wounds was 4.07 per 1000 among inpatients in Sichuan. The most common complex wounds were pressure ulcers (1.47 per 1000 among inpatients). Older, male, Han ethnic groups and retired people were most likely to suffer from complex wounds. The median LOS was longer for those with complex wounds as their main condition of treatment compared with all-cause admissions in Sichuan (12 days compared with 7 days; $p<0.001)$. The median cost of care for people with complex wounds was higher than for admission for any cause ( $¥ 6500.18$ compared with $¥ 3337.16 ; p<0.001)$. People with pressure ulcers had the longest LOS, while people with ulcers related to diabetes incurred the highest costs.

Conclusions Complex wounds, especially pressure ulcers, are common in Sichuan province and their presence is associated with significantly longer lengths of hospital stay and higher medical costs. Additionally, this study only included admitted inpatients during the sampling time period, hence the prevalence of complex wounds may be underestimated. The high prevalence rate and heavy direct and indirect disease burden of complex wounds indicate that health policies for early detection and prevention of complex wounds in elders are urgently needed.

\section{INTRODUCTION}

Complex wounds (wounds with superficial, partial or full-thickness skin loss healing by secondary intention), such as foot ulcers, legs ulcers, pressure ulcers, open trauma and surgical wounds, heal slowly and are complex to treat and care for ${ }^{12}$ : They are often referred to as chronic wounds. ${ }^{3}$ Complex wounds have been shown to adversely affect the healthrelated quality of life of those affected as they

\section{Strengths and limitations of this study}

- This geographically defined study is the first to report the prevalence and disease burden of complex wounds in inpatients in China.

- Both disease code International Statistical Classification of Diseases and Related Health Problems 10th Revision and disease diagnosis were used in this study to make sure that complex wounds were correctly identified and classified.

- As this was based on secondhand data, we were unable to identify the patients who may have had complex wounds that were not recorded in discharge records.

- This study only included admitted inpatients during the sampling time period, hence the prevalence of complex wounds may be underestimated.

are often painful and can become infected. ${ }^{45}$ Complex wounds can lead to amputation, ${ }^{67}$ which causes physical and mental harm, and severely affect productivity. Patients with complex wounds have a higher mortality than people without. $^{8} 9$ Management of complex wounds is costly, with crudely estimated annual costs of $£ 3$ billion in the UK, $\$$ A2.85 billion in Australia and US $\$ 25$ billion in the USA. ${ }^{10}$ In Europe, it has been estimated that $2 \%-4 \%$ of healthcare budgets are spent on wound management. ${ }^{11}$

Epidemiological estimates of complex wounds prevalence vary. It was estimated that 6.5 million patients have chronic wounds in the USA and $1 \%$ of population would experience wounds problem in Denmark..$^{12} 13$ In 2003, Rodrigues and Mégie conducted a cross-sectional study that included 149 Canadian local community service centres, and found the point prevalence of chronic wounds (including pressure ulcer, venous ulcer and diabetic foot wound) among home care patients was $1.4 \% .{ }^{14}$ Using health insurance data, Heyer et al showed that $1.04 \%$ of 
insured German patients had chronic wounds (including diabetic foot ulcer, pressure ulcer and leg ulcer), and $0.43 \%$ of them had leg ulcer, which was the most common wound in $2012 .{ }^{15}$ Recently, Hall et al and Gray et al have conducted community-based multiservice, cross-sectional surveys in the UK, which found that the point prevalence of complex wounds was $1.47 \%$ in Leeds and $1.64 \%$ o in the north of England, and among the most frequent wound type was leg ulcer. ${ }^{110}$ The same survey was carried out in Slovenia and found that the point prevalence of open surgical wounds was $0.38 \%{ }^{4}{ }^{4}$

Epidemiological research on complex wounds in China is limited. In 1998, Fu et al screened 30000 hospitalised surgical patients in 15 Chinese hospitals for chronic dermal ulcers and found that the incidence of wounds was from $1.5 \%$ to $3.0 \%$, with trauma and infection being the main causes. ${ }^{16}$ In 2008, similar surveys were conducted in 17 tertiary hospitals in 14 Chinese provinces, showing the prevalence of chronic wounds was 1.69 per 1000 inpatients and the leading causes were diabetes and trauma in inpatients. ${ }^{17}$ As both studies focused only on specific hospitals, the results may not allow inference on the point prevalence of complex wounds for inpatients national wide. Furthermore these data are now over a decade old and changing population demographics may result in changes in estimates. In this study, we systematically analysed hospital discharge data from Sichuan province during the fourth quarter of calendar year 2018, aiming to investigate the period prevalence of complex wounds among the overall inpatients, and the impact of complex wounds on inpatient health expense and length of hospital stay (LOS).

\section{CONTEXT}

The Chinese healthcare system is characterised by a threetier delivery system. The rural three-tier system comprises village clinics, township health centres (THCs) and county hospitals; while the urban regions have community health centres/stations (CHCs), city hospitals including district hospitals, and municipal/regional hospitals. Additionally, the county and city hospitals are classified into three levels - primary, secondary and tertiary — with supposedly increasing quality based on their clinical quality, service quality, management quality, medical safety, and clinical skills and research. ${ }^{18}$ THCs and CHCs are called primary healthcare institutions which mainly provide primary care and public health services. While primary healthcare institutions have a gatekeeping role to reduce people directly accessing specialist hospital services, patients can still go directly to higher level hospitals for medical services without attending THCs or CHCs first. Thus, in China, hospitals de facto provide both primary and specialist care; a significant difference from most healthcare systems in developed countries. When people are discharged from healthcare institutions (primary healthcare institution or hospital), their discharge records, containing demographic details together with data about their diagnoses and medical care costs, are completed by the chief physician (see online supplemental appendix table A1). These administrative data provide an opportunity to study the number of people with complex wounds in more detail. To ensure that data from all relevant people were considered, we included discharge data from all patients from primary healthcare institutions (THCs/ CHCs) and from (primary/secondary/tertiary) hospitals.

In China, over $95 \%$ of residents have social health insurance (New Cooperative Medical Scheme for the rural population; Urban Resident Basic Medical Insurance for the unemployed urban people; Urban Employee Basic Medical Insurance for urban workers), which covers access to all primary healthcare institutions and public hospitals, and some private hospitals. ${ }^{19}$ The inpatient costs for people with social health insurance consisted of two parts-out-of-pocket payments and insurance reimbursement, while almost all the outpatient cost are out of pocket. Hence, this study assumed that most, if not all, patients with complex wounds would get inpatient service, instead of outpatient service from healthcare institutions.

This study focused on Sichuan province. The results from Sichuan are likely to be applicable to much of China. Sichuan is the fifth largest and the third most populous province in China $(83.41$ million people recorded in 2018). The distribution of economic development is uneven, the geographic environment is varied and the composition of the population is diverse. West Sichuan is sparsely populated, mountainous with poor economic development, and east Sichuan is densely populated, plain with well economic development, more healthcare institutions (seeonline supplemental appendix figure A1). This is roughly consistent with the overall situation in China. ${ }^{20} 21$

\section{METHODS}

\section{Study population and data source}

Between 1 September 2018 and 31 December 2018, a total of 4033763 people were admitted to 6056 healthcare institutions across Sichuan province. All were included in this retrospective, data-based study. Individual-level information was extracted from discharge records provided by the Health Information Centre of Sichuan Province. When performing data analysis, all healthcare institutions were categorised based on their situation at the time of data collection (ie, in calendar year 2018).

\section{Classification of cases}

All people admitted with complex wounds or who developed one or more complex wounds during their stay were identified according to the International Statistical Classification of Diseases and Related Health Problems 10th Revision (ICD-10) (see table 1) and the corresponding diagnosis in discharge records. This included people with pressure ulcers of stage 2 or above, ${ }^{22}$ ulcers in people with diabetes, venous leg ulcers, non-healing surgical wounds and other ulcers (leg ulcers, upper limb ulcers, skin 
Table 1 International Statistical Classification of Diseases and Related Health Problems 10th Revision classification associated with complex wounds

\begin{tabular}{|c|c|}
\hline $\begin{array}{l}\text { Wound } \\
\text { types }\end{array}$ & Identifying methods \\
\hline $\begin{array}{l}\text { Pressure } \\
\text { ulcer }\end{array}$ & $\begin{array}{l}\text { Code L89.-, excepting grade } 1 \text { pressure ulcer } \\
\text { coded L89.000 }\end{array}$ \\
\hline \multirow[t]{4}{*}{$\begin{array}{l}\text { Diabetic } \\
\text { ulcer }\end{array}$} & $\begin{array}{l}\text { 1) Code E10.504, E11.504, E14.501, E10.505, } \\
\text { E11.505 }\end{array}$ \\
\hline & $\begin{array}{l}\text { 2) Code E11.502 with the corresponding diagnosis } \\
\text { containing 'gangrene' }\end{array}$ \\
\hline & $\begin{array}{l}\text { 3) E14.606, E11.601, E11.503, E10.503, BD54 } \\
\text { excepting these whose Wagner classification is } \\
\text { level zero. }\end{array}$ \\
\hline & 1) or 2) or 3) \\
\hline $\begin{array}{l}\text { Venous } \\
\text { leg ulcer }\end{array}$ & Code 183.0-, 183.2- \\
\hline \multirow{4}{*}{$\begin{array}{l}\text { Non- } \\
\text { healing } \\
\text { surgical } \\
\text { wound }\end{array}$} & 1) Code T81.3- \\
\hline & $\begin{array}{l}\text { 2) Code T81.4- excepting biliary tract infection } \\
\text { after surgery coded T81.404 }\end{array}$ \\
\hline & $\begin{array}{l}\text { 3) Code T81.8- excepting abdominal pain after } \\
\text { surgery }\end{array}$ \\
\hline & 1) or 2) or 3) \\
\hline $\begin{array}{l}\text { Other } \\
\text { ulcer }\end{array}$ & Code L97.-, L98.4-, R02, T87.4-, T87.5- \\
\hline
\end{tabular}

ulcers, gangrene, infection of amputation stump). We did not include people with open, traumatic wounds or burns in this study.

\section{Statistical analysis}

All analyses were performed using statistical analysis system RV.3.5.1. All point prevalence estimates were produced using the binomial proportion and are presented alongside $95 \%$ CIs. The inpatient point prevalence of complex wounds was estimated using the number of people with at least one wound (the numerator) and all inpatients as denominator. To get a crude estimate of the point prevalence of complex wounds in community-based population, this study assumed that all people with one or more complex wounds received inpatient service from healthcare institutions and the point prevalence of complex wounds for community-based population was estimated using people living in Sichuan at present and with at least one complex wound (the numerator) and the population of Sichuan in $2018^{23}$ as the denominator.

When estimating the direct disease burden (median of LOS and medical costs) of complex wounds, only people whose principal cause of hospitalisation (principal diagnosis) was the complex wound were included. Wilcoxon rank-sum test and Kruskal-Wallis rank-sum test were used to test if LOS and expense were statistically different between groups. We also extracted data on people whose principal cause of hospitalisation was not the complex wound but who were recorded as having a complex wounds of relevance in this study as a comorbidity (ie, though the patient did have one or more complex wound, their main reason for admission was not the wound), and compared their LOS and inpatient costs with patients without complex wounds to determine the additional effect of complex wounds on LOS and inpatient costs. Multivariable linear regression was fitted to control for potentially confounding factors, which were documented. Since the confounders are multilevel in our study, we constructed a two-level hierarchical linear model, where level 1 covariables included the patient's age, gender, occupation, social insurance programme, whether or not surgery was required, and Charlson Index (a widely used tool to measure comorbid disease status; a higher score equals worse health condition) adjusting for non-complex wound related comorbidity ${ }^{24}$; level 2 covariables included healthcare institution level type (tertiary hospital, secondary hospital, primary hospital, unassigned hospital, primary healthcare institution and others) and ownership type (public or private). Healthcare institutions were included as a random effect to account for the within institution correlation for patients admitted in the same institution.

To avoid the impact of incorrect records on disease burden estimates, when analysing the effect of complex wounds on LOS and inpatient expense, observations were selected based on the following criteria: (1) the LOS was at least 1 day and (2) the per capita inpatient expense was more than $¥ 100$. Thus, ultimately, 4026725 records were used for multivariable disease burden analysis.

\section{Patient and public involvement}

Neither patients nor members of the public were involved in the study design or conduct of this study.

\section{RESULTS}

\section{Prevalence of complex wounds}

A total of 16426 cases of patients with complex wounds was identified from the records of 4033763 patients during the fourth quarter of calendar year 2018. The point prevalence of complex wounds was 4.07 per 1000 of inpatients (95\% CI: 4.01 to 4.13 ) and 0.19 per 1000 of the whole population in Sichuan province (95\% CI: 0.19 to 0.20 ) (table 2). It should be noted that this prevalence is likely underestimated as it is almost certain that not all patients with complex wounds had been admitted. Pressure ulcers were the most common complex wound with a point prevalence of 1.47 per 1000 of inpatients $(95 \% \mathrm{CI}$ : 1.43 to 1.50$)$ and 0.07 per 1000 of the whole population (95\% CI: 0.07 to 0.07 ).

Table 3 shows the point prevalence estimates for all complex wounds by demographic characteristics. Most inpatients with complex wounds were aged between 60 and 79 years. The prevalence of complex wounds among inpatients increased with age, and was lowest in patients younger than 10 and highest in patients over 90 . Males had higher point prevalence estimate (5.05 per 1000 
Table 2 Wounds point prevalence estimates by wounds type

\begin{tabular}{|c|c|c|c|}
\hline Wounds type & Frequency & $\begin{array}{l}\text { Point } \\
\text { prevalence } \\
\text { per } 1000\end{array}$ & $95 \% \mathrm{CI}$ \\
\hline \multicolumn{4}{|c|}{ Inpatient point prevalence* } \\
\hline All wounds & 16426 & 4.07 & (4.01 to 4.13 ) \\
\hline Pressure ulcers & 5915 & 1.47 & (1.43 to 1.50$)$ \\
\hline Diabetic ulcers & 3269 & 0.81 & (0.78 to 0.84$)$ \\
\hline Venous leg ulcers & 1139 & 0.28 & $(0.270 .30)$ \\
\hline $\begin{array}{l}\text { Non-healing } \\
\text { surgical wounds }\end{array}$ & 4090 & 1.01 & (0.98 to 1.05$)$ \\
\hline Other ulcer & 2013 & 0.50 & (0.48 to 0.52$)$ \\
\hline \multicolumn{4}{|c|}{ Point prevalence in community-based population $†$} \\
\hline All wounds & 16086 & 0.19 & (0.19 to 0.20$)$ \\
\hline Pressure ulcers & 5842 & 0.07 & (0.07 to 0.07 ) \\
\hline Diabetic ulcers & 3230 & 0.04 & (0.04 to 0.04$)$ \\
\hline Venous leg ulcers & 1116 & 0.01 & (0.01 to 0.01$)$ \\
\hline $\begin{array}{l}\text { Non-healing } \\
\text { surgical wounds }\end{array}$ & 3936 & 0.05 & (0.05 to 0.05$)$ \\
\hline Other ulcers & 1962 & 0.02 & (0.02 to 0.03 ) \\
\hline
\end{tabular}

*Using the total number of inpatient in Sichuan province during the fourth quarter of calendar year 2018 as denominator. †Using inpatients who were living in Sichuan at present and have at least one wounds we defined as the numerator and the population of Sichuan in 2018 as the denominator.

with $95 \%$ CI 4.95 to 5.15 ) than females (3.19 per 1000 with $95 \%$ CI 3.12 to 3.27 ). Prevalence was higher for Han (Chinese) than ethnic minorities at 4.17 per $1000(95 \%$ CI: 4.11 to 4.23$)$ compared with 2.28 per 1000 (95\% CI: 2.08 to 2.49 ). Of the 16426 patients with complex wounds, most were agricultural labourers from rural areas, and the highest point prevalence estimate occurred in retired people with 10.24 per 1000 (95\% CI: 9.80 to 10.71). After adjusting for age, the prevalence of complex wounds was still significantly different by gender (likelihood ratio test: $\mathrm{p}<0.001$ ), ethnicity (likelihood ratio test: $\mathrm{p}<0.001$ ) and occupation (likelihood ratio test: $\mathrm{p}<0.001$ ).

Figure 1 shows the point prevalence estimates with $95 \%$ CIs for individual complex wound types by demographic characteristics. Prevalence rates for individual wound types increased with age except for venous leg ulcers and non-healing surgical wounds whose highest rates occurred in $60-69$ (0.50 per 1000 ; $95 \%$ CI: 0.45 to 0.55$)$ and $50-59$ years old ( 1.45 per $1000 ; 95 \%$ CI: 1.36 to 1.56$)$, respectively. The highest point prevalence rates for pressure ulcers, diabetic ulcers and other ulcers were found in patients aged 90 years and over, which were 13.48 per 1000 (95\% CI: 12.30 to 14.78 ), 1.68 per 1000 (95\% CI: 1.30 to 2.18) and 1.56 per 1000 (95\% CI: 1.19 to 2.05), respectively. Children younger than 10 were the least likely to have any complex wounds. Pressure ulcers are the most prevalent complex wound of those studied while venous leg ulcers are the least common, and females have much
Table 3 Inpatient wounds point prevalence estimates by demographic characteristics

\begin{tabular}{|c|c|c|c|c|}
\hline Variable & $\begin{array}{l}\text { Patients } \\
\text { with } \\
\text { wounds }\end{array}$ & $\begin{array}{l}\text { Total } \\
\text { patients }\end{array}$ & $\begin{array}{l}\text { Point } \\
\text { prevalence } \\
\text { per } 1000^{\star}\end{array}$ & $95 \% \mathrm{Cl}$ \\
\hline \multicolumn{5}{|l|}{ Age group $\dagger$} \\
\hline $0-9$ & 95 & 423706 & 0.22 & (0.18 to 0.27$)$ \\
\hline $10-19$ & 171 & 98270 & 1.74 & (1.50 to 2.02 ) \\
\hline $20-29$ & 462 & 293458 & 1.57 & (1.44 to 1.72$)$ \\
\hline $30-39$ & 584 & 281722 & 2.07 & (1.91 to 2.25 ) \\
\hline $40-49$ & 1569 & 480648 & 3.26 & (3.12 to 3.43 ) \\
\hline $50-59$ & 2489 & 571865 & 4.35 & (4.19 to 4.53 ) \\
\hline $60-69$ & 3763 & 835686 & 4.50 & (4.36 to 4.65 ) \\
\hline $70-79$ & 3885 & 715667 & 5.43 & (5.26 to 5.60 ) \\
\hline $80-89$ & 2825 & 299432 & 9.44 & (9.10 to 9.79 ) \\
\hline $90+$ & 583 & 33309 & 17.50 & $\begin{array}{l}\text { (16.15 to } \\
18.97)\end{array}$ \\
\hline \multicolumn{5}{|l|}{ Gender } \\
\hline Male & 9676 & 1916399 & 5.05 & (4.95 to 5.15$)$ \\
\hline Female & 6746 & 2114331 & 3.19 & (3.12 to 3.27 ) \\
\hline Missing & 4 & 3033 & 1.32 & (0.51 to 3.39 ) \\
\hline \multicolumn{5}{|l|}{ Ethnic group } \\
\hline Minority & 471 & 206921 & 2.28 & (2.08 to 2.49 ) \\
\hline Han & 15955 & 3826844 & 4.17 & (4.11 to 4.23 ) \\
\hline \multicolumn{5}{|l|}{ Occupation } \\
\hline $\begin{array}{l}\text { Civil servants } \\
\text { and active } \\
\text { army }\end{array}$ & 88 & 20341 & 4.33 & (3.51 to 5.33 ) \\
\hline $\begin{array}{l}\text { Professionals } \\
\text { and technical }\end{array}$ & 96 & 33195 & 2.89 & (2.37 to 3.53 ) \\
\hline $\begin{array}{l}\text { Office clerk } \\
\text { and manager }\end{array}$ & 347 & 103284 & 3.36 & (3.03 to 3.73 ) \\
\hline Worker & 356 & 82198 & 4.33 & (3.91 to 4.80 ) \\
\hline $\begin{array}{l}\text { Agricultural } \\
\text { labourer }\end{array}$ & 6284 & 1816499 & 3.46 & (3.38 to 3.55 ) \\
\hline Student & 133 & 103659 & 1.28 & (1.08 to 1.52 ) \\
\hline Freelancer & 427 & 98469 & 4.34 & (3.95 to 4.77 ) \\
\hline $\begin{array}{l}\text { Self- } \\
\text { employed }\end{array}$ & 63 & 19021 & 3.31 & (2.59 to 4.24 ) \\
\hline Unemployed & 491 & 124972 & 3.93 & (3.60 to 4.29 ) \\
\hline Retired & 1934 & 188829 & 10.24 & (9.80 to 10.71$)$ \\
\hline Others & 6207 & 1443296 & 4.30 & (4.20 to 4.41$)$ \\
\hline
\end{tabular}

*Using the total number of inpatient people in Sichuan province during the fourth quarter of calendar year 2018.

†Continuous variable was transferred to 10 year age categories manually.

lower prevalence of all kinds of wounds than males. Prevalence rates for individual wound types were higher for Han (Chinese) than ethnic minorities except for non-healing surgical wounds. The prevalence for individual complex wound types are highly different in occupation groups. The highest prevalence for pressure ulcer (5.89 per 1000 ; 95\% CI: 5.56 to 6.25 ) and diabetic ulcer (2.56 per 1000; 95\% CI: 2.35 to 2.80 ) both occurred in retired patients. Venous leg ulcer, non-healing surgical wounds and other 

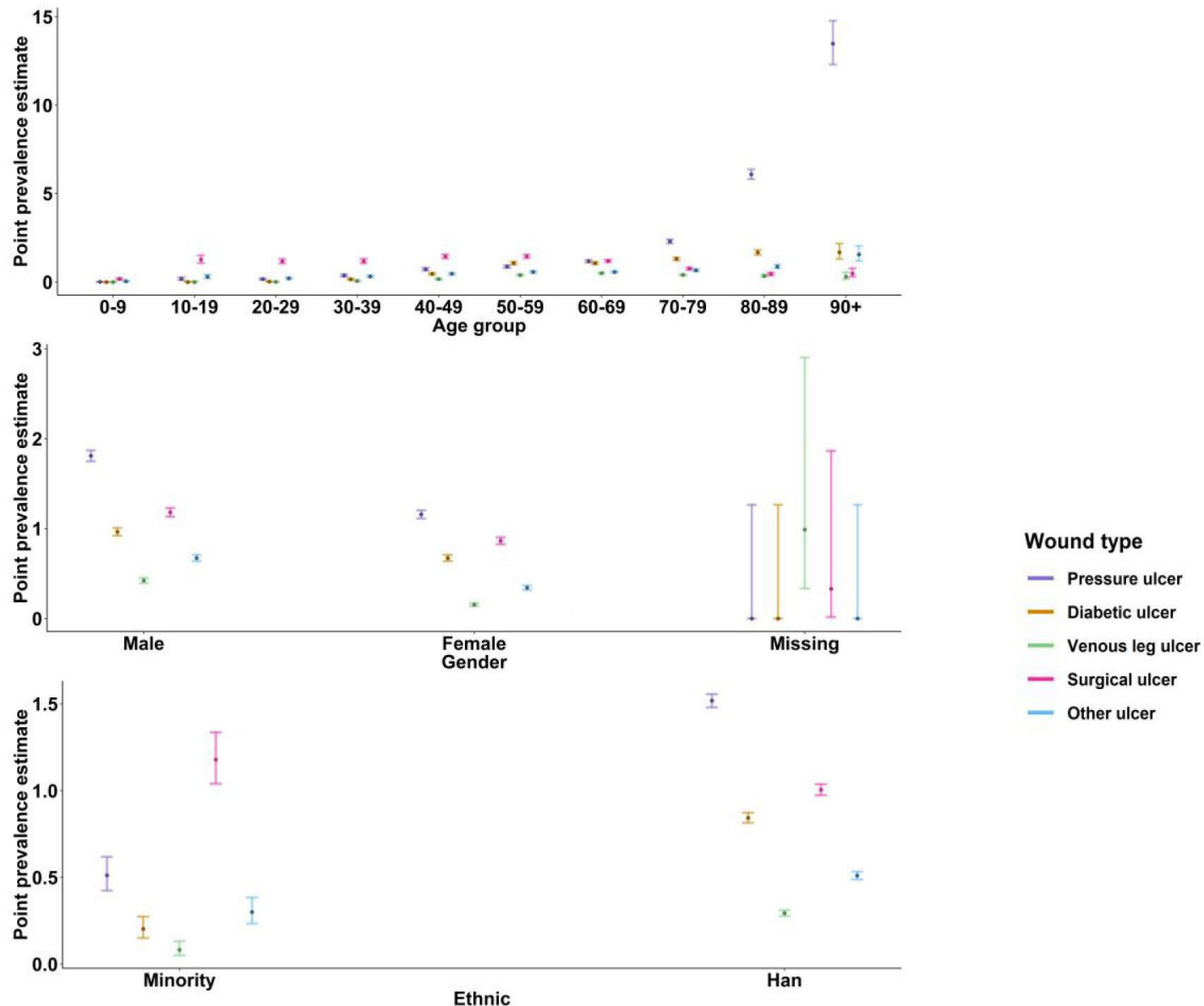

- Other ulcer

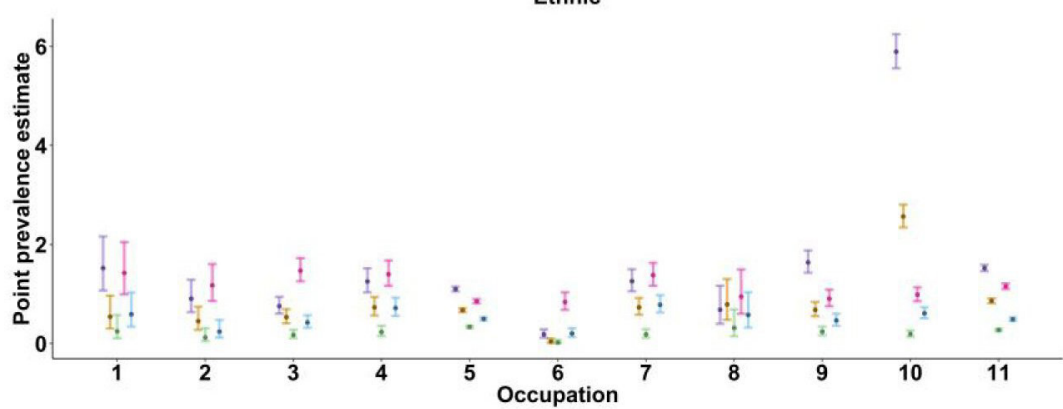

Figure 1 Inpatient wounds point prevalence estimates by wound types and demographic characteristics. Point estimates with 95\% Clss were displayed in this figure. Occupation (1) civil servants and active army; (2) professionals and technical; (3) office clerk and manager; (4) worker; (5) farmer; (6) student; (7) freelancer; (8) self-employed; (9) unemployed; (10) retired and (11) others. Exact data were showed in online supplemental appendix table A1.

ulcer were most common in agricultural labourers $(0.34$ per 1000; $95 \%$ CI: 0.31 to 0.36$)$, office clerks $(1.47$ per 1000; $95 \%$ CI: 1.26 to 1.73$)$ and freelancers ( 0.78 per 1000; $95 \%$ CI: 0.63 to 0.98$)$, respectively.

\section{Disease burden}

Table 4 shows the central tendency and dispersion of per capita hospital LOS and medical costs for inpatients whose principal diagnosis was a complex wound. The median per capita LOS was 12 days (IQR: 7-22), which is significantly longer than the median per capita LOS for all inpatient in Sichuan (median: 7 days; IQR: $4-10 ; p<0.001$ ). The median per capita medical cost for people with a complex wound was $¥ 6500.18$ (IQR: 2965.92-12 975.23); nearly double the care costs of inpatients without complex wounds (median: 3,337.16; IQR: 1759.02-6703.08; $\mathrm{p}<0.001$ ). Patients with a principal diagnosis of pressure ulcer had the longest LOS (median: 20 days; IQR: 9-34). The median per capita LOS for patients whose principal diagnosis was diabetic ulcer, venous leg ulcer, surgical ulcer or other ulcer were 13 days (IQR: 7-22), 9 days (IQR: 7-14), 11 days (IQR: 7-20) and 13 days (IQR: 7-24), respectively $(\mathrm{p}<0.001)$. Diabetic ulcers costed the most among all types of complex wounds in this study, with a median per capita medical expense of ¥8399.13 (IQR: 3435.24-16267.55) followed by pressure ulcers (median: 8039.12; IQR: 3693.78-17022.96) $(\mathrm{p}<0.001)$. 
Table 4 Disease burden of complex wounds

\begin{tabular}{|c|c|c|c|c|c|}
\hline \multirow[b]{2}{*}{ Wounds type } & \multirow[b]{2}{*}{ Frequency* } & \multicolumn{2}{|c|}{ Length of stay (days) $\dagger$} & \multicolumn{2}{|c|}{ Per capita inpatient cost $(¥) \dagger$} \\
\hline & & Mean \pm SD & Median (IQR) & Mean \pm SD & Median (IQR) \\
\hline All wounds & 5048 & $18 \pm 22$ & $12(7-22)$ & $11347.54 \pm 167150.62$ & $6500.18(2965.92-12975.23)$ \\
\hline Diabetic ulcers & 843 & $18 \pm 23$ & $13(7-22)$ & $13528.74 \pm 179660.84$ & $8399.13(3435.24-16267.55)$ \\
\hline Venous leg ulcers & 903 & $12 \pm 8$ & $9(7-14)$ & $8865.53 \pm 6866.72$ & 7496.02 (4063.37-11388.46) \\
\hline
\end{tabular}

*Only patient whose principal cause of hospitalisation was the complex wound were included in this table.

†Mean with SD and median with IQR were presented.

Table 5 shows the comorbidity of inpatients included in this study. People with complex wounds averagely have higher Charlson Index (more serious comorbidities) than people without at 1.87 compared with $0.82(\mathrm{p}<0.001)$. People with diabetic ulcers have the most serious comorbidities (Charlson Index: 3.08), followed by people with pressure ulcers (Charlson Index: 2.38), as compared with people having other complex wounds or without any complex wounds.

For patients with a complex wound which was not considered the main cause of hospitalisation, controlling other confounders, the LOS was on average $47.7 \%$ $(\exp (0.39)-1)$ longer than the LOS for patients without complex wounds (first column of table 6); the inpatient medical cost was also $60.0 \%(\exp (0.47)-1)$ higher on average (second column of table 6). Compared with patients without complex wounds, the presence of a complex wound was associated with increased LOS and increased costs. After controlling for severity of comorbidities and other confounders, we found people with nonhealing surgical wounds alongside another main reason for hospital admission had the longest LOS and highest costs: with an LOS $155.7 \%(\exp (0.939)-1)$ higher and inpatient cost $124.8 \%(\exp (0.81)-1)$ greater compared with those without complex wounds or with other types of complex wounds (pressure ulcers, venous leg ulcers or other ulcers) (the third and fourth column of table 6).

\begin{tabular}{|c|c|c|}
\hline \multirow[b]{2}{*}{ Group } & \multicolumn{2}{|c|}{ Charlson Index } \\
\hline & Mean \pm SD & Median (IQR) \\
\hline $\begin{array}{l}\text { Patients without complex } \\
\text { wounds }\end{array}$ & $0.82 \pm 1.29$ & $0(0-1)$ \\
\hline Patients with complex wounds & $1.87 \pm 1.93$ & $1(0-3)$ \\
\hline Pressure ulcers & $2.38 \pm 1.86$ & $2(1-3)$ \\
\hline Diabetic ulcers & $3.08 \pm 1.97$ & $3(1-4)$ \\
\hline Venous leg ulcers & $0.51 \pm 1.03$ & $0(0-1)$ \\
\hline Non-healing surgical wounds & $0.91 \pm 1.46$ & $0(0-2)$ \\
\hline Other ulcers & $1.17 \pm 1.58$ & $1(0-2)$ \\
\hline
\end{tabular}

\section{DISCUSSION}

Complex wounds are a challenging public health problem. ${ }^{25}$ In this study, we used 3 months of hospital

\begin{tabular}{|c|c|c|c|c|}
\hline \multirow[b]{2}{*}{$\begin{array}{l}\text { Explaining } \\
\text { variables }\end{array}$} & \multicolumn{4}{|c|}{ Dependent variable } \\
\hline & $\log ($ LOS) & $\begin{array}{l}\text { Log } \\
\text { (expense) }\end{array}$ & Log (LOS) & $\begin{array}{l}\text { Log } \\
\text { (expense) }\end{array}$ \\
\hline & -1 & -2 & -3 & -4 \\
\hline \multirow{2}{*}{$\begin{array}{l}\text { Complex wounds } \\
\text { (vs NO) }\end{array}$} & $0.39^{\star \star \star}$ & $0.47^{\star \star \star}$ & & \\
\hline & -0.01 & -0.01 & & \\
\hline
\end{tabular}

Wounds type (vs patients without complex wounds)

\begin{tabular}{|c|c|c|c|}
\hline \multirow[t]{2}{*}{ Pressure ulcers } & & $0.23^{\star \star \star}$ & $0.48^{\star \star \star}$ \\
\hline & & -0.01 & -0.01 \\
\hline \multirow[t]{2}{*}{ Diabetic ulcers } & & $0.18^{\star \star \star}$ & $0.19^{\star \star \star}$ \\
\hline & & -0.01 & -0.01 \\
\hline \multirow[t]{2}{*}{ Venous leg ulcers } & & $0.27^{\star \star \star}$ & $0.14^{\star *}$ \\
\hline & & -0.04 & -0.04 \\
\hline \multirow{2}{*}{$\begin{array}{l}\text { Non-healing } \\
\text { surgical wounds }\end{array}$} & & $0.94^{\star \star \star}$ & $0.81^{\star \star \star}$ \\
\hline & & -0.01 & -0.01 \\
\hline \multirow[t]{2}{*}{ Other ulcers } & & $0.38^{\star \star \star}$ & $0.33^{\star \star \star}$ \\
\hline & & -0.02 & -0.02 \\
\hline Observations $†$ & $4021677 \quad 4021677$ & 4021677 & 4021677 \\
\hline
\end{tabular}

Cells contain coefficient (and SE). ${ }^{* *} \mathrm{p}<0.01,{ }^{\star \star *} \mathrm{p}<0.001$. All models had adjusted for patient's age (continuous, years), gender (male, female or missing), occupation (11 categories: civil servants and active army, professionals and technical, office clerk and manager, worker, agricultural labourer, student, freelancer, self-employed, unemployed, retired, others), social insurance programme (4 categories: Urban Employee Basic Medical Insurance, Urban Resident Basic Medical Insurance, New Rural Cooperative System), whether or not surgery was required (yes or no), Charlson Index (continuous, adjusting for comorbidity), healthcare institution level (6 categories: primary hospitals, secondary hospitals, tertiary hospitals, unassigned hospitals, primary healthcare sectors, other providers) and ownership type (public or private). The full results were displayed in online supplemental appendix table A2. †Only patients whose principal cause of hospitalisation was not complex wound were selected to fit the two-level hierarchical models.

LOS, length of stay. 
discharge data from Sichuan province, China, and included all the healthcare institutions providing inpatient service in 2018. Our aim was to acquire more reliable estimates of the complex wound disease burden for inpatients. To identify patients with complex wounds more accurately, disease diagnosis and ICD-10 were used simultaneously.

This study discovered that the point prevalence of complex wounds among inpatients was 4.07 per 1000 , which is much higher than the earlier estimate from the 17 tertiary hospitals in China (1.69 per 1000 inpatients). ${ }^{17}$ Pressure ulcers were found to be the most common type of complex wound; similar to the result of an Irish study focusing on community care setting, ${ }^{26}$ a 2 -week crosssectional survey in Leeds, ${ }^{1}$ and Dutch study focusing on nursing homes. ${ }^{5}$ Our point prevalence estimate of pressure ulcers among inpatients (1.47 per 1000) is much lower than that of Indonesian inpatients $(8.0 \%)$, and German inpatients (2.25\%). ${ }^{28}$ Assuming all patients with complex wounds got inpatient service from healthcare institutions, we have crudely estimated the point prevalence of complex wounds among community-based population in Sichuan (0.19 per 1000). This rate is significantly lower than the estimates in previous studies which ranging from $0.04 \%$ to $1 \% .^{25}$

Many studies have previously shown that the prevalence of complex wounds is higher in older people, ${ }^{14} 29$ and our point prevalence rates of most complex wounds (including pressure ulcers, diabetic and other ulcers) are consistent with the highest rates occurring in age $90+$ age group. It is worth noting that the highest rates of venous leg ulcers and non-healing surgical wounds occurred in age 60-69 and 50-59 groups, respectively. For nonhealing surgical wounds, this may due to the preference of conservative treatment for elderly population in China. For venous leg ulcers, the reason of this point prevalence peak in this age group requires further investigation.

This study also found that females have lower rates of complex wounds in China than males, which is consistent with previous study conducted in China and Slovenia, ${ }^{4,16,17}$ but different from the UK ${ }^{10}$ — which showed that females are more likely to suffer from complex wounds. ${ }^{30}$ The difference may be partially explained by differences in occupational and lifestyle activities with heavy labour and activities such as smoking being more common in older men than women of the same age. Due to rapidly improving working environments and other risk factor related activities there may be a shift in these gender differences for wound point prevalence over subsequent generations.

This study found that where complex wounds was the major reason for hospital admission people had a significantly longer hospital LOS and higher medical costs than for all-cause admission in Sichuan. This is the first investigation of this kind in China. For patients who were admitted to healthcare institutions mainly for pressure ulcer, the LOS was longer than other complex wounds. Pressure ulcers often occur in people with limited mobility due to physical or cognitive impairment, and people with pressure ulcers were more likely to have serious co-morbidities. The relatively poor psychological, behavioural and cognitive status of these patients may prolong the treatment period. The longest LOS may also partially explain why the median of per capita medical expense for those admitted with a pressure ulcer is higher than for people being admitted for most other types of complex wounds. Among all the complex wound types in this study, people with diabetes and one or more ulcers incurred the most medical costs with a median per capita medical expense of $¥ 8399.13$. Again these were people commonly affected by a range of other comorbidities and who also required the use of blood glucose controlling drugs. Considering that the average yearly disposable income of Sichuan province is $¥ 20580$, this is a significant economic pressure to these patients. Median medical costs show similar trends, while differences between median and average costs likely reflect different basic costs of them. We also found that LOS and costs for people with complex wounds for whom this was not their principal diagnosis were higher when compared with patients without complex wounds. These data provide us a scope for further in-depth investigation and a hint for designing better prevention and financial support system for patients in China.

\section{Strengths and limitations}

This geographically defined study is the first to report the prevalence of complex wounds in inpatients in China using data from all healthcare institutions providing inpatient services during the study period. It is also the first to quantify disease burden of complex wounds in China. Both disease code (ICD-10) and disease diagnosis were used to make sure that complex wounds were correctly identified and classified.

This study also had some limitations. The estimates of prevalence may be underestimated. When estimating the prevalence of complex wounds for inpatients, this study was unable to identify the patients who may have had complex wounds that were not recorded in discharge records. This is also the case for patients with certain other illnesses or systematic problems, which may contribute to increased medical costs due to their links to the wounds. The point prevalence of complex wounds for the whole population in Sichuan does not capture the information of people who may have complex wounds but receive care at outpatient sectors or/and do not receive inpatient care during the study period but are 'self-treating'. Besides, basing on hospital discharge data, we were unable to identify whether the wounds were hospital acquired or pre-existed, we may have ignored the heterogeneity between these two conditions when measuring the effect of complex wounds on LOS and costs. Further research in this area could pay attention to these problems.

Acknowledgements The authors are grateful to Health Information Centre of Sichuan Province for providing data. 
Contributors ZL and JP conceived the idea and design for this study; ZL and QJ were responsible for data analysis; JP, JCD and NC contributed to data analysis; QJ created the original draft of this manuscript. All authors contributed to the interpretation of the findings, critical version of the manuscript.

Funding This study was funded by Sichuan Science and Technology Program (2019JDJQ0028).

Map disclaimer The depiction of boundaries on this map does not imply the expression of any opinion whatsoever on the part of $B M J$ (or any member of its group) concerning the legal status of any country, territory, jurisdiction or area or of its authorities. This map is provided without any warranty of any kind, either express or implied.

Competing interests None declared.

Patient consent for publication Not required.

Provenance and peer review Not commissioned; externally peer reviewed.

Data availability statement Data may be obtained from a third party (Health Information Centre of Sichuan Province, China) and are not publicly available.

Supplemental material This content has been supplied by the author(s). It has not been vetted by BMJ Publishing Group Limited (BMJ) and may not have been peer-reviewed. Any opinions or recommendations discussed are solely those of the author(s) and are not endorsed by BMJ. BMJ disclaims all liability and responsibility arising from any reliance placed on the content. Where the content includes any translated material, BMJ does not warrant the accuracy and reliability of the translations (including but not limited to local regulations, clinical guidelines, terminology, drug names and drug dosages), and is not responsible for any error and/or omissions arising from translation and adaptation or otherwise.

Open access This is an open access article distributed in accordance with the Creative Commons Attribution Non Commercial (CC BY-NC 4.0) license, which permits others to distribute, remix, adapt, build upon this work non-commercially, and license their derivative works on different terms, provided the original work is properly cited, appropriate credit is given, any changes made indicated, and the use is non-commercial. See: http://creativecommons.org/licenses/by-nc/4.0/.

\section{ORCID iDs}

Qingling Jiang http://orcid.org/0000-0001-7773-393X

Jay Pan http://orcid.org/0000-0001-9501-1535

\section{REFERENCES}

1 Hall J, Buckley HL, Lamb KA, et al. Point prevalence of complex wounds in a defined United Kingdom population: point prevalence of complex wounds. Wound Repair Regen 2014;22:694-700.

2 Jiang Y, Xia L, Jia L, et al. Survey of wound-healing centers and wound care units in China. Int J Low Extrem Wounds 2016;15:274-9.

3 Han G, Ceilley R. Chronic wound healing: a review of current management and treatments. Adv Ther 2017;34:599-610.

4 Pađen L, Griffiths J, Cullum N. A cross-sectional survey of patients with open surgical wounds in Slovenia. Health Soc Care Comm 2018:hsc. 12700.

5 Rondas AALM, Schols JMGA, Stobberingh EE, et al. Prevalence of chronic wounds and structural quality indicators of chronic wound care in Dutch nursing homes. Int Wound J 2015;12:630-5.

6 Lindholm C, Bergsten A, Berglund E. Chronic wounds and nursing care. J Wound Care 1999;8:5-10.

7 Viswanathan V. Epidemiology of diabetic foot and management of foot problems in India. Int J Low Extrem Wounds 2010;9:122-6.

8 Hansson C, Andersson E, Swanbeck G. A follow-up study of leg and foot ulcer patients. Acta Derm Venereol 1987;67:496-500.
9 Gibbons GW, Orgill DP, Serena TE, et al. A prospective, randomized, controlled trial comparing the effects of noncontact, low-frequency ultrasound to standard care in healing venous leg ulcers. Ostomy Wound Manage 2015;61:16-29.

10 Gray TA, Rhodes S, Atkinson RA, et al. Opportunities for better value wound care: a multiservice, cross-sectional survey of complex wounds and their care in a UK community population. BMJ Open 2018;8:e019440.

11 Pokorná A, Leaper D. Assessment and documentation of nonhealing, chronic wounds in inpatient health care facilities in the Czech Republic: an evaluation study. Int Wound J 2015;12:224-31.

12 Sen CK, Gordillo GM, Roy S, et al. Human skin wounds: a major and snowballing threat to public health and the economy. Wound Repair Regen 2009;17:763-71.

13 Gottrup F. A specialized wound-healing center concept: importance of a multidisciplinary department structure and surgical treatment facilities in the treatment of chronic wounds. Am J Surg 2004;187:S38-43.

14 Rodrigues I, Mégie M-F. Prevalence of chronic wounds in Quebec home care: an exploratory study. Ostomy Wound Manage 2006;52:46-57.

15 Heyer K, Herberger K, Protz K, et al. Epidemiology of chronic wounds in Germany: analysis of statutory health insurance data. Wound Repair Regen 2016;24:434-42.

16 Fu X, Sheng Z, Cherry GW, et al. Epidemiological study of chronic dermal ulcers in China. Wound Repair Regen 1998:6:21-7.

17 Jiang Y, Huang S, Fu X, et al. Epidemiology of chronic cutaneous wounds in China: epidemiology of chronic wounds in China. Wound Repair Regen 2011;19:181-8.

18 Wang X, Yang H, Duan Z, et al. Spatial accessibility of primary health care in China: a case study in Sichuan Province. Soc Sci Med 2018;209:14-24.

19 Keqiang L. Deepen health care reform continously and promote the establishment of the health care system that suits China's national conditions and benefits all people. Available: http://www.gov.cn/ldhd/ 2011-11/17/content_1995480.htm

20 Pan J, Shallcross D. Geographic distribution of hospital beds throughout China: a county-level econometric analysis. Int J Equity Health 2016;15:179.

21 Wang X, Pan J. Assessing the disparity in spatial access to hospital care in ethnic minority region in Sichuan Province, China. BMC Health Serv Res 2016;16:399.

22 Raetz JGM, Wick KH. Common questions about pressure ulcers. Am Fam Physician 2015;92:888-94.

23 National Bureau of Statistics of China. National data by Province, 2018. Available: http://data.stats.gov.cn/easyquery.htm?cn=E0103\& $\mathrm{zb}=\mathrm{A} 030801 \& \mathrm{reg}=510000 \& \mathrm{sj}=2018$

24 Sundararajan V, Henderson T, Perry C, et al. New ICD-10 version of the Charlson comorbidity index predicted in-hospital mortality. J Clin Epidemiol 2004;57:1288-94.

25 Martinengo L, Olsson M, Bajpai R, et al. Prevalence of chronic wounds in the general population: systematic review and metaanalysis of observational studies. Ann Epidemiol 2019;29:8-15.

26 McDermott-Scales L, Cowman S, Gethin G. Prevalence of wounds in a community care setting in Ireland. J Wound Care 2009;18:405-17.

27 Amir Y, Lohrmann C, Halfens RJ, et al. Pressure ulcers in four Indonesian hospitals: prevalence, patient characteristics, ulcer characteristics, prevention and treatment: pressure ulcers in four Indonesian hospitals. Int Wound J 2017;14:184-93.

$28 \mathrm{Kr} \&$ ouml;ger K, Niebel W, Maier I, et al. Prevalence of pressure ulcers in hospitalized patients in Germany in 2005: data from the federal statistical office. Gerontology 2009;55:281-7.

29 Wicke C, Bachinger A, Coerper S, et al. Aging influences wound healing in patients with chronic lower extremity wounds treated in a specialized wound care center. Wound Repair Regen 2009;17:25-33.

30 Agale SV. Chronic leg ulcers: epidemiology, aetiopathogenesis, and management. Ulcers 2013;2013:1-9. 